\title{
Preliminary Study on Deltamethrin Residues in Cahbage, Soil and Water from Dalaguete, Cebu, Philippines
}

\author{
Armstrong Calinawan ${ }^{1}$, Concepcion S. Mendoza ${ }^{2}$ and Leonila Adarna ${ }^{1^{*}}$ \\ ${ }^{1}$ Chemistry Department, University of San Carlos, Cebu City \\ ${ }^{2}$ Department of Mathematics and Sciences, German University of Technology in Oman, Muscat, Oman
}

Pesticides pose a threat to the environment and eventually human health. Extent of contamination of pesticides can be determined and monitored by analysis of pesticide residue in surface water, sediments, soil, and biota. Samples were collected from Manlapay, Barangay Mantalongon in Dalaguete, reportedly the vegetable basket of Cebu, from October to November 2013. Concentration of the pesticide deltamethrin was determined by Gas Chromatography-Electron Capture Detector along with organic matter content $(\mathrm{OM})$, potassium $(\mathrm{K})$ and cation exchange capacity (CEC) using standard methods of analysis. Data showed that deltamethrin was found to be present in soil and cabbage and beyond detection limit in water. Inverse relationship was found between residue in cabbage and in soil confirming pesticide leaching as supported by rainfall data. Organic matter and cation exchange capacity in soil showed significant correlation to detected deltamethrin residue confirming that pyrethroids are strongly bound to organic matter and free exchangeable potassium ions. Deltamethrin residue in water does not show any correlation to any other parameters as it is beyond detection limit, probably due to volatilization and photodegradation of deltamethrin in water. Temperature variation does not show significant difference to deltamethrin residue in all three matrices. The detected deltamethrin residue concentrations in the cabbage $(<0.001-0.029$ ppm), soil samples (0.007-0.008 ppm) and water samples $(<0.0005 \mathrm{ppm})$ were all below international guideline limits (ASEAN maximum level of $0.5 \mathrm{ppm}$ deltamethrin in cabbage, EC ecologically accepted concentration of $1290 \mathrm{mg}$ deltamethrin $/ \mathrm{kg}$ soil, and a maximum limit of $0.0025 \mathrm{ppm}$ deltamethrin according to Canadian water quality, respectively). Inspite of the low concentrations detected in cabbage, soil and water samples, an extensive pesticide monitoring on environmental samples within the area is advisable. This will help the adoption of an efficient risk assessment strategy to inform appropriate interventions.

Keywords: deltamethrin; cabbage; water; soil; Cebu, Philippines

INTRODUCTION
Agriculture is still the most common form of employment in the Philippines and the current industrial agricultural system depends much 
on agrochemicals like pesticides and synthetic fertilizer. Pesticides have been widely used in agriculture due to its profit based advantages which includes better crop quality, higher farm yield and minimal labor requirement (Chen et al., 2011, Osman et al., 2010).

The commonly used chemical pesticides are carbamates, organophosphates, organochlorines and pyrethroids. Pyrethroids are synthetic pyrethrum derivative which are widely used to control insect pests due to their high insecticidal potency (Zhou et al., 2011). Both, market and scientific interests on pyrethroids had also increased due to its characteristics of being readily decomposed under ultra-violet rays and as neurotoxicants with low mammalian toxicity (Soderlund et al., 2002).

Deltamethrin is one type of active ingredient belonging to the type II pyrethroid pesticides, which is approved for use in the Philippines (DA-FPA 2007), as substitute to the highly toxic pesticides. Deltamethrin [IUPAC name: (S)- $\alpha$-cyano-3-phenoxybenzyl (1R,3R)-3-(2,2dibromovinyl)-2,2-dimethylcyclopropane carboxylate and molecular formula of $\left.\mathrm{C}_{22} \mathrm{H}_{19} \mathrm{Br}_{2} \mathrm{NO}_{3}\right]$ is a slightly water soluble compound with very low vapor pressure and high phostostability, making it one of the less readily degraded pesticide and allowing the possibility of accumulation to environmental sinks. Deltamethrin is considered the most powerful and most toxic of the pyrethroids (EXTOXNET, 1996). Deltamethrin residues are expected to be distributed with different ratio in vegetation, soil, water, air, living creatures and crops resulting to several ecological risks, particularly by causing algal blooms, toxicity to aquatic organisms and reducing bee populations and associated pollination service (EXTOXNET, 1996). Deltamethrin can remain long time in the soil, and are absorbed by the crops, and eventually flow out of the arable land to the surrounding environments. Deltamethrin can also bioaccumulate in the food web and pose adverse effect on humans. Deltamethrin was also found to cause a variety of acute health conditions on humans (INCHEM, 1990;
EXTOXNET, 1996; PAN, 2010), but can be prevented with necessary precautions.

Studies on toxic effects of deltamethrin are very less (Rehman, et al., 2014). There is the need to investigate the toxic effects of deltamethrin and other pyrethroids and to reduce pesticide risks to humans and the environment. In the Philippines, though pesticides are used extensively, but related pesticide studies are also limited (Davis, 1993). Even simple data on pesticide residue level in areas where the pesticide is used is not easily available due to lack of analytical technology. In this study, deltamethrin residues in cabbage, in soil and in water were assessed to obtain preliminary information on the status of deltamethrin residues in one of the Cebucabbage growing areas; from Manlapay, Barangay Mantalongon in Dalaguete, reportedly the vegetable basket of Cebu. Some factors that may affect the transport and persistence of deltamethrin are also studied.

\section{EXPERIMENTAL}

Description of Sampling Site and Sample Collection. The study was conducted in an agricultural farm in Manlapay, Mantalongon, Dalaguete, Cebu. The farm uses terracing techniques to prevent soil erosion and rapid nutrient leaching. The terraces has 3 steps and each is called an andene. Each andene is about 150 square meters in area. A two-meter buffer zone was set for each andene. Each step of the andene was designated as top, middle and bottom sites for cabbage and soil sampling purposes. Table 1 shows the GPS coordinates of the sampling site. Sampling was done during October to November 2013.

Table 1: GPS Coordinates of the Sampling Sites.

\begin{tabular}{|c|c|c|c|}
\hline $\begin{array}{c}\text { Sample } \\
\text { Collected }\end{array}$ & $\begin{array}{c}\text { Area } \\
\text { Assignment }\end{array}$ & $\begin{array}{c}\text { GPS } \\
\text { Coordinates }\end{array}$ & Elevation \\
\hline $\begin{array}{c}\text { Cabbage and } \\
\text { Soil }\end{array}$ & Top & $\begin{array}{l}\mathrm{N} 09^{\circ} 52^{\prime} 16.9^{\prime \prime} \\
\mathrm{E} 123^{\circ} 29^{\prime} 01.1^{\prime \prime}\end{array}$ & $595 \mathrm{~m}$ \\
\hline $\begin{array}{l}\text { Cabbage and } \\
\text { Soil }\end{array}$ & Mid & $\begin{array}{l}\mathrm{N} 09^{\circ} 52^{\prime} 16.4^{\prime \prime} \\
\text { E } 123^{\circ} 29^{\prime} 01.6 "\end{array}$ & $592 \mathrm{~m}$ \\
\hline $\begin{array}{l}\text { Cabbage and } \\
\text { Soil }\end{array}$ & Bottom & $\begin{array}{l}\text { N } 09^{\circ} 52^{\prime \prime} 16.9^{\prime \prime} \\
\text { E } 123^{\circ} 29^{\prime} 02.4 "\end{array}$ & $578 \mathrm{~m}$ \\
\hline Water & Water Effluent & $\begin{array}{l}\mathrm{N} 09^{\circ} 52^{\prime} 28.3^{\prime \prime} \\
\mathrm{E} 123^{\circ} 28^{\prime} 30.3^{\prime \prime}\end{array}$ & $554 \mathrm{~m}$ \\
\hline
\end{tabular}


For each sampling site, at least five six-inch deep holes were one meter away from each other. Composite soil samples were collected from the holes, combined and placed in properly labelled re-sealable plastic bag and temporarily stored in a cooler with ice before transporting it to the laboratory.

Four cabbage heads, heads and roots, were randomly collected per andene. Soil strongly bound to the root system, the rhizosphere, was mixed with the composite soil samples before all the cabbages were mixed. Cabbage samples were placed in properly labelled resealable plastic bags and temporarily stored in a cooler with ice before transporting it to the laboratory.

Water samples were collected from the water catchment located downhill about 20 meters from the farm. One liter of water effluent was collected and placed in acid-washed polypropylene bottles and stored in a cooler with ice.

Deltamethrin Pesticide Analysis. The analytical samples were taken and prepared accordingly (Thier et al., 1991).

Water. About $1 \mathrm{~g} \mathrm{NaCl}$ was added to $50 \mathrm{~mL}$ water, shaken with $50-\mathrm{mL}$ portions of hexane on a filtered water sample. The filtered hexane layer was dried on $\mathrm{Na}_{2} \mathrm{SO}_{4}$ and concentrated to near dryness in a rotary evaporator at a water bath temperature of $40^{\circ} \mathrm{C}$.

Soil. A $15 \mathrm{~g}$ of homogenized, screened and air dried samples and spiked soil samples were obtained and added with $80 \mathrm{~mL}$ acetone. Approximately $10 \mathrm{~g}$ of anhydrous $\mathrm{Na}_{2} \mathrm{SO}_{4}$ was added and the mixture was shaken for 1 hour. The mixture was filtered and the residue further washed with $20 \mathrm{~mL}$ of acetone. The combined filtrate was concentrated to near dryness in a rotary evaporator at a water bath temperature $40{ }^{\circ} \mathrm{C}$.

Cabbage. A $15 \mathrm{~g}$ of homogenized samples were obtained, added with $60 \mathrm{~mL}$ hexane-acetone mixture for 3 mins. The mixture was filtered and to the organic phase was shaken with three $50-\mathrm{mL}$ portions of acetonitrile for 1 minute. Approximately $6.2 \mathrm{~g}$ of anhydrous $\mathrm{MgSO}_{4}$ was added and the mixture was vigorously shaken for 1 minute. The mixture was centrifuged and about six millilitres of the clear liquid solution was allowed to pass through a C18 column and eluted with $20 \mathrm{~mL}$ dichloromethane. The eluent was concentrated to near dryness in a rotary evaporator at a water bath temperature of $40{ }^{\circ} \mathrm{C}$.

Extraction and GC-ECD Injection. The remaining extracts collected during water sample preparation was redissolved with $5 \mathrm{~mL}$ of $n$-hexane: acetone mixture (70:30) and sonicated for complete dissolution. A florisil solid phase extraction cartridge was conditioned and washed with $5 \mathrm{~mL}$ of of $n$ hexane followed by $5 \mathrm{~mL}$ of $n$-hexane-acetone mixture (70:30). Samples were then loaded to the prepared cartridge and eluted with $10 \mathrm{~mL}$ $n$-hexane:acetone mixture (70:30). The eluate was collected, evaporated to near dryness, redissolved with $2 \mathrm{~mL}$ and injected into the GC instrument.

The above step was also done for extracts collected during soil sample preparation. Similar step as stated above was performed for the extract collected during cabbage sample preparation. However, instead of using hexane-acetone mixture, acetonitrile was used in the washing the florisil solid phase cartridge and in the GC elution process.

Table 2. GC-ECD working condition

\begin{tabular}{l|l}
\hline $\begin{array}{l}\text { Injector } \\
\text { temperature }\end{array}$ & $250^{\circ} \mathrm{C}$ \\
\hline $\begin{array}{l}\text { Detector } \\
\text { Temperature }\end{array}$ & $300^{\circ} \mathrm{C}$ \\
\hline $\begin{array}{l}\text { Oven } \\
\text { Temperature } \\
\text { Program }\end{array}$ & $\begin{array}{l}120^{\circ} \mathrm{C} \text { hold for } 1 \text { minute, } \\
9{ }^{\circ} \mathrm{C} / \mathrm{min} \text { to } 285^{\circ} \mathrm{C}\end{array}$ \\
\hline Carrier Gas & Nitrogen $(\mathrm{GC}$ grade $)$ \\
\hline Make-up Gas & Hydrogen $(\mathrm{GC}$ grade $)$ \\
\hline $\begin{array}{l}\text { Column Flow } \\
\text { Rate }\end{array}$ & $3.0 \mathrm{~mL} / \mathrm{min}$ \\
\hline Column & $2.7 \mathrm{~m} \times$ mm i.d. glass on $5 \%$ \\
\hline Amount Injected & 2 microliters \\
\hline Data System & HP Chem Station \\
\hline
\end{tabular}


GC-ECD Analysis. The extracts were analyzed for deltamethrin content using a Shimadzu AA360. The working condition for the GCECD analysis is summarized in Table 2.

Other Analyses on Soil and Water Samples. All chemicals used were of reagent grade. The Orion $\mathrm{pH}$ meter for $\mathrm{pH}$ determination and Shimadzu AA 360 atomic absorption spectrophotometer for potassium analysis were used. The various parameters: organic matter in soil (Walkey-Black method); chemical oxygen demand (COD) in water (dichromate open reflux method or Tinsley's wet combustion method); cation exchange capacity of soil (ammonium acetate method); and potassium in soil and water (flame atomic emission spectroscopy) were determined using recommended procedures (Latimer, 2012; Rice et al., 2012; Radojevic et al., 1999). Working standards solutions were prepared by diluting the stock solution with deionized water. The precision of the measurements was checked taking at least two replicates from the samples and including a blank in each batch.

Rainfall and Ambient Temperature Measurement. Rainfall and temperature data was obtained from the Department of Science and Technology, Philippine Atmospheric geophysical and Astronomical Services Administration at Mantalongon Station, Dalaguete.

Quality Assurance. External calibration method and standard spiking was done for the determination of deltamethrin in the samples analyzed. Recovery tests were also performed through solid and liquid matrices.

\section{RESULTS AND DISCUSSION}

The sampling site chosen for the environmental fate of deltamethrin was an agricultural farm in Barangay Manlapay, Dalaguete, Cebu. The farm is sloping with uneven ground and is divided unequally into three distinct land mass separated by piles of rocks strategically built to prevent soil erosion, where cabbage is a common crop. Cabbage is a common cultivar of the species Brassica oleracea Linne var. Capitata and used as a leafy vegetable.
During its growth process, cabbage gets damaged by many insects and pathogens such as Myzus persicae, Plutella xylostella L., Spodoptera exigua Hubner, Pbyllotreta striolata Fabricus, bacterial soft rot, downy mildew (Zhang et al., 2008, Du et al., 2002) and prevented by the use of deltamethrin pesticide.

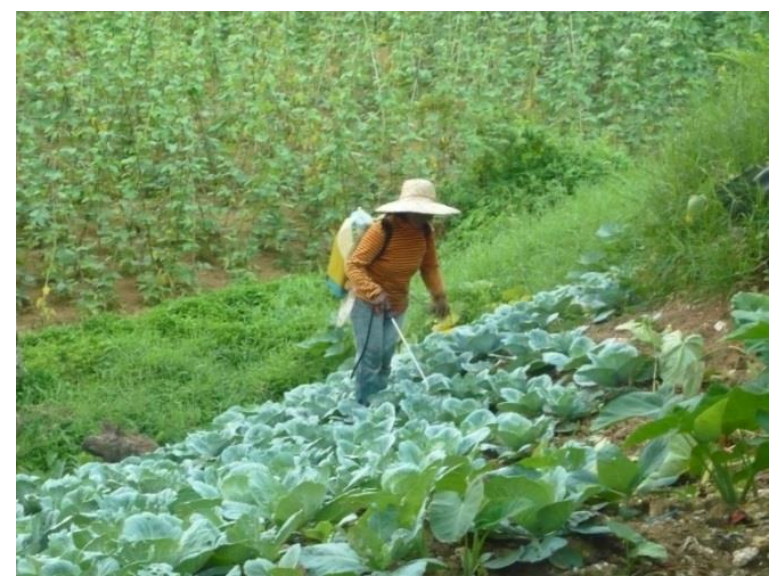

Figure 1: A Local Farmer Spraying a Cocktail Pesticide to Cabbages.

Cocktailing is a common practice in pesticide application in the Philippines. A dose of one pesticide is mixed with a dose of another in the same dilution volume which makes the resulting solution very potent. Application is done twice a month or as often as needed to prevent pest attack, as shown in Figure 1. On the event of a big infestation, the recommended dose of the pesticide is increased using the same dilution volume as if normal allowable concentration. Two sets of pesticides are usually used per commodity. One of these set of pesticides is deltamethrin (with brand name Astro) was used.

Soil, water and cabbage samples were collected once a month during October to November 2013 and analysed for the set parameters. Deltamethrin residue analysis was done on the environmental samples collected including control samples. During deltamethrin residue analysis, fortification of control samples and recovery percentages from spiked samples were done. The average recovery was $83.39 \%$ in the solid matrix and $94.45 \%$ in the liquid matrix. The results of the analysis have shown that there is occurrence of deltamethrin in water, soil and cabbage as shown in Table 3. 
Table 3. Deltamethrin Concentration in Collected Samples.

\begin{tabular}{|c|c|c|c|c|c|}
\hline \multirow{2}{*}{ Month } & \multicolumn{3}{|c|}{ Deltamethrin, ppm } & \multirow[b]{2}{*}{ *Rainfall, mm } & \multirow[b]{2}{*}{${ }^{*}$ Temperature, ${ }^{\circ} \mathrm{C}$} \\
\hline & Cabbage & Soil & Water & & \\
\hline October 2013 & $0.029 \pm 0.00$ & $0.007 \pm 0.00$ & $<0.0005$ & 154.6 & $18.7-23$ \\
\hline November 2013 & $<0.001$ & $0.008 \pm 0.00$ & $<0.0005$ & 240.8 & $17.6-23$ \\
\hline
\end{tabular}

*[PAG-ASA 2013]

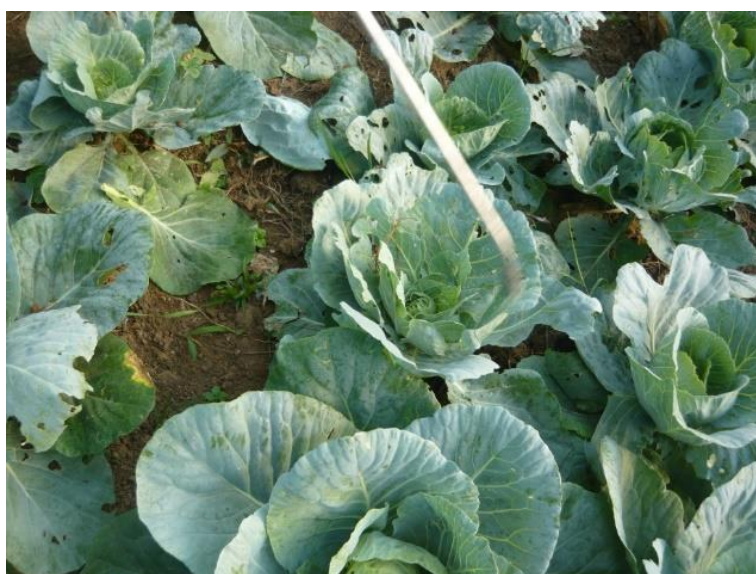

Figure 2. Pesticide Application Directly Sprayed on the Cabbage Heads.

In general, deltamethrin is observed to be highest in concentration in cabbage head followed by soil sample and least in water sample. This result is expected as pesticide application is primarily directed to cabbage heads as shown in Figure 2, prior to harvest or when there is infestation (Chen et al., 2011) while its presence in soil and water is due to spray loss, wind drift, atmospheric deposition and/or leaching phenomena (Jiang et al., 2012; Norum et al., 2010; Hippelein and McLachlan, 2000; Wang et al., 2006).

Residue level in cabbage during October 2013 is higher than in November 2013 due to

Table 4. Some Physical Properties and Deltamethrin Residues in the Soil and Water Sampled.

\begin{tabular}{lcccc}
\hline \multirow{2}{*}{ Property } & \multicolumn{2}{c}{ Soil } & \multicolumn{2}{c}{ Water } \\
\cline { 2 - 5 } & Oct 2013 & Nov 2013 & Oct 2013 & Nov 2013 \\
\hline Deltamethrin, ppm & $0.007 \pm 0.00$ & $0.008 \pm 0.00$ & $<0.0005$ & $<0.0005$ \\
\hline Organic matter, ppm & $5.19 \times 10^{4} \pm 3,832$ & $5.46 \times 10^{4} \pm 1,818$ & - & - \\
\hline $\begin{array}{l}\text { Oxidizable organic } \\
\text { carbon, ppm COD }\end{array}$ & - & - & $2.01 \times 10^{3} \pm 6.1$ & $1.30 \times 10^{3} \pm 4.0$ \\
\hline Total Potassium, ppm & $20.47 \pm 0.8$ & $17.85 \pm 0.2$ & $271.51 \pm 20.6$ & $420.49 \pm 0.5$ \\
\hline $\begin{array}{l}\text { Cation Exchange } \\
\begin{array}{l}\text { Capacity }(\mathrm{CEC}), \\
\text { meq/100g }\end{array}\end{array}$ & $30.5 \pm 0.8$ & $36.0 \pm 0.6$ & - & - \\
\hline $\mathrm{pH}$ & $6.97 \pm 2.03$ & $7.01 \pm 0.03$ & $6.50 \pm 0.01$ & $6.80 \pm 0.0$ \\
\hline
\end{tabular}
application, and of weather conditions. The cabbages in October 2013 were sprayed twice, while the cabbages in November 2013 were of the second harvest and were sprayed only once prior to sample collection. This result is consistent with the results of Zhang et al., (2008) which showed the close relationship of amount of pesticide residues with dosage of application, and with weather conditions after spraying. Table 3 also shows that the amount of rainfall in November is larger than the rainfall in October. In such wet situation, the dispersion of pesticide residue maybe easier to other areas. The lower pesticide residue in November maybe caused by the washing out of the adsorbed pesticides on the cabbage leaves. The high amount of precipitation during the wet months of October and November may have permitted the leaching of pesticide from the vegetable to the soil (Akesson et al., 2013; Alegria et al., 2000).

Other factors that may affect the accumulation of deltamethrin in soil and in water samples are determined, and result of analyses is presented in Table 4. differences in frequency of pesticide 
There is a higher deltamethrin concentration detected in soil than in water as deltamethrin has high affinity to the solid phase (Yang et al., 2006), and has low water solubility (USDHHS 2004, EC 2002). As shown in Table 4, the organic content is determined in two ways. The determination of soil organic matter used the Walkley-Black Method, which is a direct way of measuring the organic matter by loss on ignition. The water organic matter was quantified using the oxidizable organic carbon Tinsley Method or as Chemical Oxygen Demand (COD) Method; an indirect way for organic matter determination. In the classic Walkley and Black method, an average of $77 \%$ of the organic matter is oxidized, whereas Tinsley's wet combustion method oxidizes most of the organic matter, facilitated by the presence of perchloric acid (Faithfull 2002). Carbon in graphite and coal may not be oxidized, thus, it is therefore preferable to report the "percentage easily oxidizable organic carbon" rather than the "percentage organic matter' using the Tinsley method. For comparison purposes on the quantification of organic matter content in soil and in water, the easily oxidizable organic carbon can be used and calculated for both samples: in soil $=41002.5 \mathrm{ppm}(=77 \%$ of the average of $\left.5.19 \times 10^{4}+5.46 \times 10^{4}\right) ;$ water $=1655 \mathrm{ppm}(=$ average of $\left.2.01 \times 10^{3}+1.30 \times 10^{3}\right)$; with the soil samples having higher value than the water samples. High organic matter content in soil increases the persistence of deltamethrin in soil. Deltamethrin is adsorbed strongly into the soil organic matter inhibiting its biodegradation and as well, with little potential to leach into groundwater (Roberts and Hutson, 1999). High organic matter in soil also provides medium for the accumulation of deltamethrin as shown by the greater residue detected in November than in October. The nearly neutral $\mathrm{pH}$ condition $(\mathrm{pH} \simeq 7$ ) of the soil prevents chemical degradation, making the persistence of deltamethrin in soil effective, too. Deltamethrin at $\mathrm{pH} 5-7\left(25^{\circ} \mathrm{C}\right)$ is stable and does not undergo hydrolytic degradation (EC, 2002). Many insecticides are susceptible to rapid pesticide breakdown under alkaline medium (Fishel, 1991).
The organic matter in water, quantified as Chemical Oxygen Demand (COD) listed in Table 4 is greater in October than in November. The relationship between organic matter in water to deltamethrin residue cannot be stated at the moment as deltamethrin concentration in water is below detection limit. Deltamethrin volatilizes in water more easily than in soil (Johnson et al., 2010) and is rapidly degraded with a half-life of 8 to 48 hours to decamethrinic acid (Erstfeld, 1999), and thus, is not expected to occur in the water samples analysed. However occurrence of deltamethrin in surface water is greatly possible depending on the rate of precipitation, event of erosion, method of application, and ambient conditions before and during application (Wang et al., 2006; Cho and Mostaghimi, 2009; Akesson et al. 2013; Alegria et al., 2000; Varca, 2012).

The higher CEC of November 2013 soil sample than that of the October 2013 can be due to salt absorption, like what occurs with halloysite (Newman et. al., 1987). The clay structure may have water molecules in between layers and the ability to adsorb large quantities of monovalent cations such as $\mathrm{NH}_{4}{ }^{+}$and $\mathrm{K}^{+}$. Such process was enhanced by more rainfall occurred in this month. Table 4 also shows that the CEC of soil sample is directly related to $\mathrm{pH}$, to deltamethrin residue, to organic matter but inversely proportional to potassium content. The CEC in soil samples is significantly correlated to $\mathrm{pH}\left(\mathrm{t}=7.91 \times 10^{-7}\right.$ for October and $t=1.30 \times 10^{-7}$ for November, $\mathrm{CL}=95 \%$ ). An increase in soil acidity or a decrease in $\mathrm{pH}$ may result in a decreased CEC owing to protonation of variable charges and reduced nutrient retention (Ludwig et al., 2001). The variable (or $\mathrm{pH}$ dependent) charge component in soils changes with $\mathrm{pH}$ due to protonation and deprotonation of functional groups on inorganic soil minerals, amorphous materials, metal oxides, oxyhydroxides, and hydroxides, and layer silicates coated with metal oxides and soil organic matter. As the soil solution becomes acidic, it causes the ionization of the hydroxyl groups on the soil surface colloids and allowing other cations ( $\mathrm{pH}$-dependent charges) bound to the soil 
colloids to push into solution. Thus, the CEC or the ability of soil to remove cations from the soil water solution is decreased. The $\mathrm{pH}$ dependent charges are variable and increase with increasing $\mathrm{pH}$. The $\mathrm{pH}$ dependent charges on oxides of $\mathrm{Fe}, \mathrm{Al}, \mathrm{Mn}$, and $\mathrm{Si}$ and organic colloids are positive at $\mathrm{pH}$ values below their isoelectric points and negative above their isoelectric points (Manahan, 2001). As a result those cations can be made available to plants but also able to be leached from the soil, possibly making the soil less fertile.

The CEC of soil organic matter are higher than those of clay minerals. It is estimated that up to $80 \%$ of the CEC in soils is due to organic matter (Stevenson, 1982). The role that soil organic matter plays is in the retention of ions is in soils. In this study, the CEC value of 30.5 and $36.0 \mathrm{meq} / 100 \mathrm{~g}$ means that the soil sample belongs to clay and clay loams category (Donahue et al., 1977). Under this soil classification, there is the presence of large amounts of organic matter, appreciable amounts of exchangeable cations, and high amounts of bioavailable nutrients. The CEC value of soil samples and the deltamethrin concentration in soil presented in Table 2 is observed to exhibit direct proportionality. Aside from CEC and organic matter relationship, other related trends are shown by the results of this study. Soil sample of November 2013 had higher CEC, higher organic matter, higher deltamethrin residue but lower potassium content as compared to the October 2013 soil sample. This is because potassium does not complex with organic compounds. Therefore, potassium availability is only minimally related to the soil's organic matter content in mineral soils. In fact, the potassium-deficient soils are those composed mostly of organic matter, such as organic soils (Foth, 1990). However, due to the very slight difference in the obtained deltamethrin residue levels between October and November 2013, further data gathering is suggested to confirm the relationship between pesticide content with CEC and the other factors mentioned in this study that may affect the accumulation of deltamethrin in environmental samples. Such information is also helpful for the implementation of agrisoil management practices.

Further, the results of this study showed that potassium in soil is significantly correlated to that in water $\left(\mathrm{t}=6.63 \times 10^{-5}\right.$ for October and $\mathrm{t}=$ $1.46 \times 10^{-4}$ for November, CL $=95 \%$ ) with inverse relationship. The greatest amount of total potassium was detected in water sample collected on November 2013, indicating more leaching happened because there was also more rainfall during the month of November. Potassium in soil could be leached by good quality rain or irrigation water releasing sorbed $\mathrm{K}^{+}$into solution (Jalali et al., 2008), thus reaching groundwater or surface water.

The mechanisms by which pesticides are retained by soil organic matter are not clearly understood. However, the pesticide may be strongly retained in the internal voids of humus molecules that are sieve-like (Khan, 1973). Adsorption of pesticides on the humic substance portion of the organic matter occurs via ion exchange and protonation, $\mathrm{H}$ bonding, van der Waals forces, ligand exchange (an organic functional group such as a carboxyl or hydroxyl) displaces an inorganic hydroxyl or water molecule of a metal ion at the surface of a soil mineral such as a metal oxide, resulting in a ligand exchange and an inner sphere complexes, and cation and water bridging (Koskinen et al., 19900).

Absorption of electrolytes from surrounding medium happens through active metabolic mechanisms. Any alteration in one of these processes results in a change in the plasma electrolyte composition. Potassium and sodium ions play a crucial role in cell functioning like maintenance of membrane potential and in regulation of cell signaling (Rao and Rao, 1996). Deltamethrin significantly alter $\mathrm{K}^{+}$current and its transport across neural membranes due to the blockage of sodium and potassium movement through the nerve membrane (DeLorenzo and Fulton, 2012). The effects of pyrethroid exposure on neuronal tissue (both insects and mammals) delay the inactivation of affected voltage gated sodium channels, allowing for an increase in 


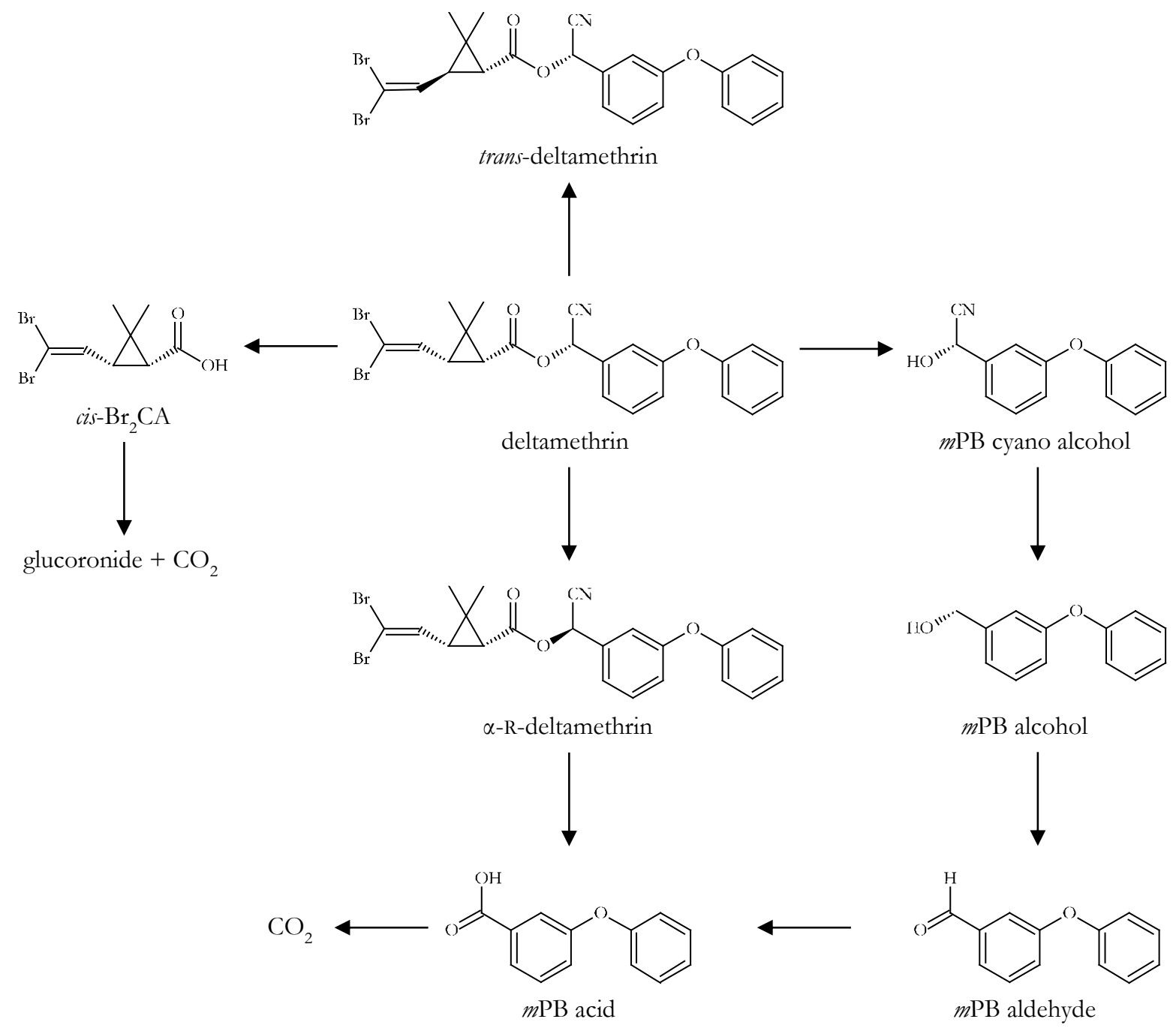

Figure 4. Degradation pathway of deltamethrin.

sodium ion influx and resulting in delayed repolarization. (Narahashi 1996; Soderlund et al., 2002; Shafer et al., 2005; Weiner et al., 2006). The delay is more pronounced in cyano-containing pyrethroids like deltamethrin $(>>200 \mathrm{~ms})$ resulting in depolarizationdependent block of the neuronal action potentials and toxicity. Thus, the possible two binding sites of $\mathrm{Na}^{+}$and $\mathrm{K}^{+}$is at the cyanogroup and at the ester linkage of deltamethrin (Gilbert et al., 2010).

In the natural environment, pyrethroids can be degraded through several possible processes, including photodegradation, biodegradation, and hydrolysis. Aerobic soil degradation of deltamethrin occurred by ester cleavage followed by oxidation and mineralisation to $\mathrm{CO}_{2}$. The only major degradation product is decamethrinic acid or
$\mathrm{Br}_{2} \mathrm{CA}$ and other potential major product which is rather an unstable $m \mathrm{~PB}$ acid (Wang, 1991a). In anaerobic soil condition, deltamethrin degradation occurred via epimerization forming a minor metabolite, $\alpha$ R-deltamethrin, followed by ester cleavage forming $\mathrm{Br}_{2} \mathrm{CA}$ and oxidation product to $m \mathrm{~PB}$ acid, then mineralization to $\mathrm{CO}_{2}$ and its incorporation into the soil biomass (Wang, 1991b). The hydrolytic degradation of deltamethrin in water at $\mathrm{pH} 9$ produces two degradation products: $m \mathrm{~PB}$ aldehyde and traces of $\mathrm{Br}_{2} \mathrm{CA}$ (Smith, 1990). Abiotic hydrolysis is unlikely to contribute significantly to the degradation of deltamethrin residues in aquatic systems unless the $\mathrm{pH}$ is high. During aqueous photolysis, deltamethrin underwent ester cleavage and cis-trans isomerization. The major photodegradation products were $m \mathrm{~PB}$ 
acid and cis- $\mathrm{Br}_{2} \mathrm{CA}$ and trans-deltamethrin was also found (Wang and Reynolds, 1991). The degradation of deltamethrin in water to decamethrinic acid is a rapid conversion (Erstfeld, 1999). Metabolism studies on crop categories fruits, cereals and oilseed demonstrated that deltamethrin was not readily degraded. In animals (rats, hens, cows), the basic metabolic reactions involve cleavage of the ester bond by oxidation and/or hydrolysis, followed by oxidation of the released acid and alcohol moieties. The acid moiety $\left(\mathrm{Br}_{2} \mathrm{CA}\right)$ is transformed into conjugates, chiefly the glucuronide, and excreted in urine. Figure 4 shows the simplified proposed metabolic pathways of deltamethrin (Liu et al., 2010; FAO 2002).

The preliminary results of this study demonstrate the occurrence of deltamethrin at very low concentrations in cabbage, soil and water from Cebu cabbage growing area, as compared to other studies detected in different environmental samples like air, waters, sediments, plants and animals (Armah, 2011; Amweg, 2005). No Philippine norms exist for pesticides and such, other international guidelines are used for comparison. In this study, the deltamethrin levels measured in cabbage were lower than the Codex and ASEAN maximum residue limit (MRL) for leafy vegetables like cabbage of $0.5 \mathrm{mg} / \mathrm{kg}$ or $0.5 \mathrm{ppm}$ (ASEAN, 2002). Though the deltamethrin content in water is below detection limit, however the limit of detection is also lower than the Canadian water quality guidelines for the protection of agricultural water uses of $2.5 \mathrm{ug} / \mathrm{L}$ or 0.0025 ppm (Kegley et al., 2014; Armah, 2011). The deltamethrin concentration found in soil samples is also lower than ecologically accepted concentration for sediments, based on the acute toxicity for earthworms, $\mathrm{LC}_{50}$ value $>1290 \mathrm{mg} / \mathrm{kg}$ soil (EC, 2002), and indicating that the Dalaguete soil is still a good environment for earthworms. Thus, ingestion of cabbage, water or soil might not be an important pathway of deltamethrin exposure because the deltamethrin values obtained from this study are less than the allowed daily intake without causing harm to humans for deltamethrin of $0.01 \mathrm{mg} / \mathrm{kg} /$ day (WHO, 2002).

The results of our study suggest that contamination by deltamethrin in Cebu cabbage growing area is not alarming. However, this study was limited to a small number of samples collected from a small representative area and in only one phase of the growing season. At the same time, the presence of deltamethrin in cabbage, soils and water in close proximity to human and animal populations should not be discounted. Further residue studies in other agricultural areas of Cebu are needed in order to assess the levels of deltamethrin and other pesticide residues in vegetables, soils, water and living organisms. With the increasing use of pesticides, a worldwide control of residue levels in foods and in the environment is needed, especially if the residue level of pesticides goes beyond the required minimum levels.

\section{ACKNOWLEDGMENT}

The researchers would like to thank Jefcor Laboratories Incorporated in Cavite, Manila and USC Water Laboratory for the support extended during the laboratory analyses; and the cooperation of the farmers of the cabbage farm in Manlapay, Mantalongon, Dalaguete, Cebu, Philippines during sample collection and to the Municipality of Dalaguete for the accommodation and transportation during the sampling.

\section{REFERENCES}

Akesson M, Sparrenbom CJ, Carlsson C and Kreuger, J. J. Hydrol. 2013; (477):165-174.

Alegria H, D'Autel JP and Shaws T. J. Mar. Pol. Bul. 2000; (12):1178-1185.

Amweg EL, Weston DP and Ureda NM. Environmental Toxicology and Chemistry. 2005; (24):966-972.

Armah FA. Research Journal of Environmental Toxicology. 2011;(5):180-202. 
ASEAN Cooperation in Food, Agriculture and Forestry. Harmonization of Maximum residue Limits (MRLs) of Pesticides for Vegetables. October 2002. (adopted by 20 $0^{\text {th }}$ ASEAN Ministers on Agriculture and Forestry (AMAF), Hanoi, 14-16 September 1998).

Chen C, Qian Y, Chen Q, Tao C, Li C and Lin Y. J. Food Cont. 2011; (22):1114-1120.

Cho J and Mostaghimi S. J. Biosystemeng. 2009; (102):473-485.

DA-FPA (Department of Agriculture, Fertilizer and Pesticide Authority, Philippines). List of Registered Agricultural Pesticide Products, as of 31 Dec 2007.

Davis C. The Science of the Total Environment. Supplement. 1993; 293-304.

DeLorenzo ME and Fulton MH. J. Mar. Pol. Bul. 2012; (64):1291-1299.

Donahue, Miller and Shickluna. Soils: an introduction to soils and plant growth, $4^{\text {th }}$ edition. (Inglewood Cliffs, New Jersey 07632: Prentice-Hall, ISBN 0-13-821918-4, 1977).

Du FL, Zhu Q and Liu J. Yangtze Vegetable. 2002; (3): 38-46.

EC (European Commission). Review report for the active substance deltamethrin: inclusion of deltamethrin in Annex I of directive 91/414/EEC. Meeting of Standing Committee on the Food Chain and Animal Health. 18 October 2002.

Erstfeld K. Chemosphere. 1999; (10): 1737-1769.

EXTOXNET (Extension Toxicology Network). 1996. Pesticide Information Profile - Deltamethrin. Accessed June 30, 2015.

Faithfull NT. Methods in Agricultural Chemical Analysis, A Practical Handbook. Oxon. UK: CAB Internatinal Publishing. 2002.

FAO. Deltamethrin (135). First draft prepared by Dugald MacLachlan, Department of Agriculture, Forestry and Fisheries, Australia. 2002. Available from: http://www.fao.org/
ag/AGP/AGPP/Pesticid/JMPR/Download/2 002_eva/DELTAMETHRINevaluationjja.pdf.

Fishel F. Pesticides and the Environment. Agricultural MU Guide (G 7520). University Extension, University of Missouri-Columbia. September 1991.

Foth HD. Fundamentals of soil science, 8th ed. John Wiley \& Sons, Inc. USA. 1990.

Gilbert LI, Gill SS (ed.). Insect control Biological and Synthetic Agents. Academic Press, Elsevier BV., USA. 2010.

Hippelein M and McLachlan MS. Environ. Sci. Technol. 2000; (34): 3521-3526.

INCHEM (International Programme on Chemical Safety). 1990. Deltamethrin. Accessed June 30, 2015.

Jalali M. Pedosphere. 2010; 20:293-303.

Jiang W, Haver D, Rust M and Gan J. Wat. Res. 2012 ;(46):645-652.

Johnson M, Luukinen B, Buhl K, Stone D. Deltamethrin Technical Fact Sheet; National Pesticide Information Center, Oregon State University Extension Services. 2010.

Kegley SE, Hill BR, Orme S and Choi AH. PAN Pesticide Database, Pesticide Action Network, North America, Oakland, CA, 2014, http:www.pesticideinfo.org (accessed March 10, 2015).

Khan SU. Can. J. Soil Sci. 1973; (53): 429-434.

Koskinen WC and Harper SS. The retention process: Mechanisms. In "Pesticides in the Soil Environment: Processes, Impacts, and Modeling” (H.H. Cheng, ed.), SSSA Book Ser. 2, pp. 51-77. Soil Sci. Soc. Am., Madison, WI. 1990.

Latimer G. Official Methods of Analysis of AOAC, $12^{\text {th }}$ edition. (AOAC International, ISBN-10: 0935584838, 2012).

Liu P, Liu Y, Liu Q, Liu J. Journal of Environmental Sciences. 2010; 22(7) 1123-1128. 
Ludwig B, Khanna PK, Anurugsa B, Folster H. Geoderma.2001; (102):27-40.

Manahan SE. Fundamentals of Environmental Chemistry, $2^{\text {nd }}$ ed., Boca Raton: CRC Press LLC, 2001.

Narahashi T. (1996). "Neuronal ion channels as the target sites of insecticides." Pharmacol Toxicol 79: 1-14.

Newman ACD and Brown G. The chemical constitution of clays. In "Chemistry of Clays and Clay Minerals" (A.C.D. Newman, ed.), Mineral. Soc. Eng. Monogr. No. 6, pp. 1-128. Longman Group Ltd., Harlow, Essex, England. 1987.

Norum U, Friberg N, Jensen MR,Johnson M, Luukinen B, Buhl K and Stone D. Deltamethrin Technical Fact Sheet. National Pesticide Information Center, Oregon State University Extension Services. 2010.

PAG-ASA (Philipppine Atmospheric and Geophysical Astronomical Services Administration). September 2013 to November 2013 Rainfall data, PAG-ASA satellite monitoring station, Mantalongon, Dalaguete, Cebu, Philippines. 2013.

PAN Pesticide Database - Chemicals. Deltamethrin. 2010. Accessed June 30, 2015.

Osman KA, Humaid AMA, Rehiayani SMA and Redhaiman KNA. J. Ecoenv. 2010; (73):1422-1439.

Radojevic $\mathrm{M}$ and Bashkin VN. Practical Environmental Analysis. (Cambridge, UK: Royal Society of Chemistry, 1999).

Rao GVand Rao KSJ. J. Neurol. Sci. 1997; (147):127-133.

Rehman H, Aziz AT, Saggu S, Abbas ZK, Mohan A, Ansari AA. Journal of Entomology and Zoology Studies. 2014; 2(6):60-70.
Rice EW, Baird RB, Eaton AD and Clesleri LS. Standard Methods for the Examination of Water and Wastewater, 22 ${ }^{\text {nd }}$ edition. (American Water Works Association/American Public Works Association/Water Environment Federation, 01/01/2012).

Roberts TR, Hutson DH. Metabolic pathways of agrochemicals: insecticides and fungicides. (Royal Society of Chemistry. 1999).

Shafer TJ, Meyer D and Crofton KM. Environ Health Persp. 2005; 113(2): 123-136.

Smith AM. 1990. Determination of aqueous hydrolysis rate constant and half-life of deltamethrin. BionomicsLaboratories. DT RA CPHY 90 SPBI A1 US43310. A45079. Unpublished.

Soderlund D, Clark J, Sheets L, Mullin L, Piccirillo V, Sargent D, Stevens J, and Weiner M. Toxicology. 2002; 171(1): 3 - 59.

Stevenson FJ. Humus Chemistry. John Wiley \& Sons, New York. 1982.

Thier HP and Kirchhoff J. (ed.). Manual of Pesticide Residue Analysis, Volume I and II. Deutsche Forschungsgemeinschaft, Pesticide Commission. Wiley VCH. 1991.

US-DHHS 2004 (U.S. Department of Health and Human Services, Agency for Toxic Substances and Disease Registry). Toxicological Profile for Pyrethrins and Pyrethroids, 2004. http://atsdr.cdc.gov/toxprofiles/tp155.html updated Apr 2004 (accessed June 9, 2015).

Varca LM. Ag Wat. 2012; (106):35-41.

Wang F, Bian YR, Jiang X, Gao HJ, Yu GF and Deng JC. Pedosphere. 2006; (16):161-168.

Wang WW. Aerobic soil metabolism of ${ }^{14} \mathrm{C}$ deltamethrin. Xenobiotics Laboratories Inc. DT EC EPSM 91 XENO A1 US89097. A47917. Unpublished. 1991a. 